\title{
Martírio e resistência em 2 Macabeus*
}

\author{
Willibaldo Ruppenthal Neto*
}

\section{Resumo}

O presente artigo visa apresentar como o livro de 2 Macabeus se constrói a partir de uma teologia do martírio, vinculada à crença na ressurreição, e uma ideologia da resistência, a qual busca enfatizar a bravura de Judas Macabeu e seus soldados no enfrentamento das tropas selêucidas. Objetiva-se explicitar o caráter judaico do livro, que recorre a elementos próprios da Bíblia Hebraica e da tradição judaica, a despeito de seu caráter literário ser próprio do estilo helenístico.

Palavras-chave: Martírio. Judaísmo. Revolta dos Macabeus. Período helenístico.

\section{Martyrdom and resistance in 2 Maccabees}

\section{Abstract}

The present article aims to present how the book of 2 Maccabees are built on a theology of martyrdom, linked to the belief in resurrection, and on an ideology of resistance, which seeks to emphasize the bravery of Judas Macabeu and his soldiers in confronting the Seleucid troops. It aims to make explicit the Jewish character of the book, which uses elements of the Hebrew Bible and the Jewish tradition, despite its literary character in Hellenistic style.

Keywords: Martyrdom. Judaism. Revolt of Maccabees. Hellenistic period.

\section{Martirio y resistencia en 2 Macabeos}

\section{Resumen}

El presente artículo pretende presentar cómo el libro de 2 Macabeos se construye a partir de una teología del martirio, vinculada a la creencia en la resurrección, y una

* Este artigo é parte de minha dissertação de Mestrado em História pela UFPR, defendida em 2018, com alterações. Tal dissertação foi empreendida com o apoio financeiro do CNPq por meio de bolsa de mestrado.

** Doutorando em História pela UFPR. Mestre em História pela UFPR (2018). E-mail: willibaldoneto@hotmail.com 
ideología de la resistencia, la cual busca enfatizar la bravura de Judas Macabeo y sus soldados en el enfrentamiento de las tropas seléucidas. Se pretende explicitar el carácter judío del libro, que recurre a elementos propios de la Biblia hebrea y de la tradición judía, a pesar de su carácter literario ser propio del estilo helenístico.

Palabras-clave: Martirio. Judaísmo. Revolta de los Macabeos. Período helenístico.

\section{Introdução}

Quando se compara as duas principais fontes a respeito da Revolta dos Macabeus - 1 e 2 Macabeus -, facilmente se percebe o quão distantes estão em seus fundamentos teológicos. Afinal, enquanto em 1 Macabeus o perdão divino se dá principalmente no derramamento do sangue dos ímpios que profanaram o Templo, em 2 Macabeus é o sangue puro dos mártires que concede o perdão divino ${ }^{1}$, transformando completamente o andamento dos eventos ${ }^{2}$. Se a perseguição é uma punição decorrente do pecado de Israel, a redenção de Israel só poderia ser alcançada pelo seu perdão. Para tal perdão, é necessário, segundo a teologia do martírio, uma expiação, que implica preferencialmente ${ }^{3}$ em sangue derramado: "A disposição para expiar é mostrada pela resistência aos comandos do rei, pela oração, pela confissão, mas sobretudo através do sacrifício de sangue” (HABICHT, 2006, p. 99).

1 "Em 1 Macabeus, a cólera divina se afastou das pessoas graças à ação purificadora dos macabeus, uma ação que consistiu em erradicar os ímpios de Israel. Aqui [2 Macabeus], ao contrário, é o sangue dos mártires e em particular dos infantes inocentes que expia os feitos do povo e permite em definitivo a ação de Judas, que não poderia ter conseguido sem a bênção divina" (BERTHELOT, 2006, p. 106, tradução nossa - todas as citações de obras de língua estrangeira foram traduzidas pelo autor). Como bem lembra C. Habicht, a morte dos recém-nascidos e circuncidados (2 Mac 6.10) é particularmente importante, sendo denominados àv $\alpha \mu \alpha \rho \tau$ tror em 2 Mac 8.4, ou seja, "inocentes de culpa pessoal" (HABICHT, 2006, p. 98, nota 29). A respeito da teologia do martírio, seus antecedentes e mesmo sua influência na teologia cristã, cf. HEARD JR., 1989.

2 Elias Bickerman lembra que "a virada nos eventos é trazida pelo sangue dos mártires" (BICKERMAN, 2007, p. 1056 [II]), mas, como bem indicado por Christian Habicht, também a culpa (pecado) havia transformado os eventos: "culpa e expiação dominam os fatores causais trazendo os pontos de virada nos eventos" (HABICHT, 2006, p. 99).

3 Apesar de $1 \mathrm{Sm} 15.22$ indicar a preferência divina pela obediência aos holocaustos, há outros textos importantes e mesmo ritos que "acentuam bastante o valor expiatório do sangue", como lembra Roland de Vaux (2008, p. 457), como Lv 17.11: "Porque a vida da carne está no sangue. E este sangue eu vo-lo tenho dado para fazer o rito de expiação sobre o altar, pelas vossas vidas; pois é o sangue que faz expiação pela vida" (tradução da Bíblia de Jerusalém [BJ]). Cf. Hb 9.22. Cabe lembrar que no Sirácida se indica que a obediência e a bondade valem como sacrifícios (Eclo 35.1-5), mas não despreza o valor dos mesmos (cf. Eclo 35.6-13). 
O martírio, neste contexto judaico, pode ser compreendido como a disposição de alguém para a morte, não por desejo de morrer (suicídio propriamente dito), mas como consequência de uma situação de perseguição na qual, para permanecer em sua fé de forma íntegra, precisa escolher pela morte. Desenvolvendo-se uma teologia sobre esta prática, ou seja, uma teologia do martírio propriamente dita, tal escolha para a morte se torna, dentro do judaísmo, uma espécie de modo de purificação, pelo qual a morte de alguém se torna expiatória. E no caminho do judaísmo nesta direção, o livro de 2 Macabeus parece ser o primeiro passo, senão um verdadeiro "salto".

\section{Martírio e expiação}

Nesta perspectiva, da mesma forma que alguns indivíduos contaminaram todo o povo mediante seus pecados ${ }^{4}$, também alguns indivíduos poderiam cancelar a culpa de todo o povo através de sua obediência, servindo como sacrifícios voluntários (HABICHT, 2006, p. 99) ${ }^{5}$. Sabendo desta condição, os sete irmãos mártires, em 2 Macabeus, tomam a decisão do martírio estando conscientes da capacidade expiatória de suas mortes: "Possa afinal deter-se, em mim e nos meus irmãos, a ira do Todo-Poderoso, que se abateu com justiça por sobre todo o nosso povo!” (2 Mac 7.38). Esta perspectiva teológica sobre a expiação, porém, aparece ainda bastante tímida em 2 Macabeus, sendo depois não somente desenvolvida como também explicitada em 4 Macabeus, onde o mártir Eleazar declara: "Faça meu sangue

Cf. 2 Mac 5.17,20; 6.14-15; 7.18,32-33,38.

5 Como bem indicado por Jarvis J. Williams, os textos de Gn 22, Êx 32, Nm 25 e Is 53 são os principais textos nos quais se sugere que a morte de uma pessoa serviria como expiação para o povo de Israel. Dentre estes quatro textos, Is 53 é o que mais se aproxima da ideia de morte expiatória. Cf. WILLIAMS, 2010, p. 64-84 [83]. Não foi à toa, portanto, que este texto foi especialmente importante na teologia cristã. Da mesma forma, como bem indicado por Jarvis J. Williams, Paulo utilizou a teologia do martírio, fundamentada em Is 53 e expressa em 2 Macabeus, em sua teologia da morte de Cristo como sacrifício expiatório. Cf. WILLIAMS, 2010, p. 85-119; Rm 3.21-26. Se, por um lado, K. Koch, H. S. Versnel, J. Schröter e outros negam a validade de Is 53 como base bíblica para a morte expiatória de um indivíduo (utilizando os seguinte textos: Dt 24.16; 2 Rs 14.6; 2 Cr 25.4; Ex 32.30-33), Roy E. Ciampa defende que tanto o autor de 2 Macabeus como Paulo encontraram em Is 53 as bases de suas teologias, cf. CIAMPA, 1998, p. 57-58 [esp. nota 85]; NICKELSBURG, 2003, p. 67. Se a teologia do martírio vale-se equivocadamente destes textos, deturpando seus significados originais, ou se o fazem corretamente, não importa para este estudo - o que importa é que a teologia de 2 Macabeus encontrou base na Bíblia Hebraica e a utilizou, seja de forma correta ou equivocada. Cf. HEARD JR., 1989, p. 7-20; 119-130; 200-300. 


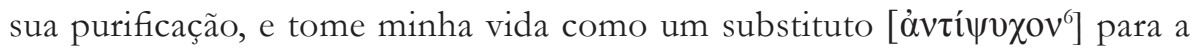
deles" (4 Mac 6.29, cf. DESILVA, 2006, p. 23).

A morte dos mártires, portanto, não é somente decorrente da perseguição de Antíoco, mas também visa apaziguar a "ira do Todo-Poderoso"

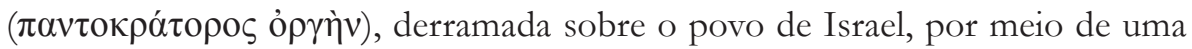
oferta expiatória. Segundo a maldição de Deuteronômio 29 (v. 19)7, a "ira"

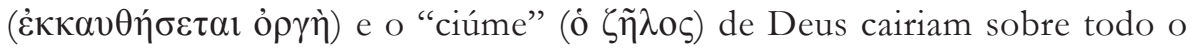
povo por causa daqueles que se afastassem dele, servindo outros deuses (cf. Dt 29.17) ${ }^{8}$. A necessidade do martírio, portanto, seguindo a influência de Deuteronômio em 2 Macabeus, resultaria da abertura dos judeus à cultura e religião gregas 9 . Este pecado, que trouxe a ira de Deus sobre o povo, criou a necessidade de perdão, possível pela morte dos mártires, como "bodes expiatórios"10. De fato, segundo Jacqueline C. R. de Roo (2000), o "bode

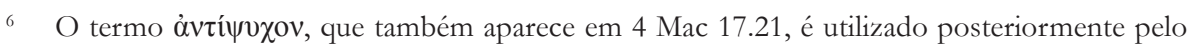
bispo Ignácio em relação à sua morte como "substituta" da morte da sua audiência (Smyr., 10.2; Eph., 21.1; Polyc., 2.3; 6.1). Segundo Rajak, não deve ser traduzido como "ransom" ("resgate", "compensação"), mas como "substitute" ("substituto"). Cf. RAJAK, 2001, p. 110, nota 38. Assim, "através do sangue destes piedosos e através da oferta propiciatória de suas mortes, a providência divina resgatou o anteriormente maltratado Israel" (4 Mac 17.22). cf. DESILVA, 2006, p. 59. A qualidade do sacrifício "sobre todo o [...] povo" (2 Mac 7.38) parece decorrer também do fato de serem sete irmãos mártires, formando "um sacrifício perfeito", cf. MCCLELLAN, 2009, p. 91

Dt 29.20 nas traduções em inglês.

8 Segundo Dt 29.18, ninguém deve pensar "Vou ter paz, mesmo que ande conforme a obstinação do meu coração, pois a abundância da água fará a sede desaparecer" (BJ, grifo nosso). Conforme bem indicado pela Bíblia de Jerusalém [BJ], outras traduções trazem o provérbio "de modo que seja arrancado o terreno irrigado com o terreno seco" (cf. NASB; ASV; SBB [alterado]; NVI [fora das aspas], etc); há ainda traduções que se referem ao ditado "acrescentar à sede a bebedeira" (cf. ACRF; ARIB; KJ, etc), enquanto a tradução grega traduziu "de modo que o pecador não seja destruído com o que não tem pecado", explicando o sentido dos provérbios. Cf. BJ, 2013, p. 295, nota b. A ideia, portanto, é a de que Deus castigaria seu povo em decorrência da adoração dos deuses, mesmo que nem todos pecassem. O pecador, portanto, não seria poupado por estar junto ao que não tem pecado. Originalmente, esta profecia se refere ao exílio do povo de Israel, a ser levado cativo para a babilônia.

9 Segundo Martha Himmelfarb, o castigo divino seria, na perspectiva de 2 Macabeus, resultado antes da abertura cultural do que da idolatria. Cf. HIMMELFARB, 1998, p. 26. Deste modo, 1 Macabeus seguiria mais fielmente a teologia de Deuteronômio, enfatizando não somente o abandono da aliança (1 Mac 1.15), mas também a adoração de outros deuses (1 Mac 1.43). Cf. 1 Mac 2.15-28.

10 Por "bode expiatório" se compreende o conjunto de práticas rituais de diversos povos nas quais um animal ou sujeito era conduzido para fora do complexo social ou sacrificado, a fim de purificar a sociedade, ou seja, na qual um indivíduo (animal ou pessoa) servia como meio de purificação do conjunto. Na Grécia Antiga, o "bode expiatório" se apresentava 
expiatório" enviado pelo povo de Israel ao deserto no dia da expiação ( $\mathrm{Lv}$ 16) ${ }^{11}$ seria justamente destinado para a "poderosa ira de Deus"12. Tal ira, aplacada todos os anos por meio de uma oferta vida, requereria, segundo 2 Macabeus, um sacrifício maior, em decorrência do pecado do povo.

O castigo divino, porém, apesar de resultar na morte de muitos judeus, não teve a pretensão de destruir Israel, sendo apenas temporário, servindo como meio de educar o povo pelo sofrimento. O próprio sofrimento, portanto, também é temporário - tanto para o povo, que logo alcança a libertação, quanto para os mártires, que na morte encontram a esperança da ressurreição. Tal ensino divino, que tem no Eclesiástico e na Sabedoria de Salomão expressões importantes (cf. Eclo 4.17-19; 18.13-14; Sb 12.2), é importante ao pecador (tal como o povo), quando tem consciência de que está sendo objeto da correção divina. O ensino divino em 2 Macabeus, porém, se destaca na ênfase da teologia da "medida por medida", cuja punição tem como propósito "desviar Israel de seus caminhos pecaminosos" (EGO, 2007, p. 154) ${ }^{13}$. A punição, nesta perspectiva de castigo e sofrimento temporários, não teria caráter destrutivo, mas educativo.

no ritual do pharmakos ( $\varphi \propto \varrho \mu \alpha x o ́ \varsigma)$, segundo o qual uma pessoa era expulsa da cidade (ou morta, segundo a mitologia). Cf. BREMMER, 1983. No meio judaico, porém, o "bode expiatório" seria literalmente um bode, como em Lv 16, enviado para o deserto. Apesar de Mary Douglas (2003, p. 123) enfatizar a diferença entre as práticas grega e judaica pelos judeus não aplicarem a prática a seres humanos, segundo Raymond Westbrook e Theodore

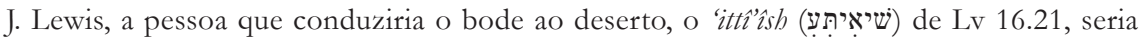
um criminoso, a ser afastado do grupo. Cf. WESTBROOK; LEWIS, 2008; MALUL, 2009. De fato, como bem indicado por K. Wengst, S. K. Williams, e mais recentemente por Henk S. Versnel (2005) e Tessa Rajak (2001), a tradição judaica do martírio (e mesmo a cristã), parecem incorporar elementos oriundos de uma tradição grega a respeito da morte vicária de indivíduos por outros, ou por uma coletividade. Cf. VERSNEL, 2005; RAJAK, 2001, p. 99-133.

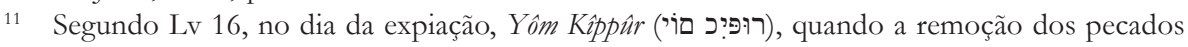
do povo se dava da forma mais elevada (cf. FEINBERG, 1958, p. 320), um bode era oferecido como sacrifício "para Deus", laYHWH (דָוֹוהיבל), enquanto outro era enviado ao

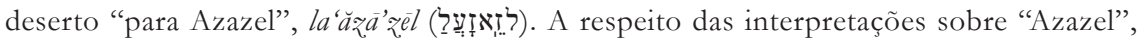
cf. RUPPENTHAL NETO, 2016a.

12 Jacqueline C. R. de Roo lembra do uso cristão do "bode expiatório", que é relacionado a Jesus Cristo na Epistola de Barnabé. Cf. EpBar 7.7.9. É evidente que a teologia cristã seguiria um caminho parecido quando se refere ao "cálice" de Jesus (cf. Mt 26.39; Mc 14.36; Lc 22.42; Jo 18.11), provavelmente relacionado ao "cálice da ira de Deus" (cf. Is 51.17,22; Jr 25.15). Cf. também Rm 3.24-25; 1 Ts 1.10; DE ROO, 2000, p. 240.

13 Sobre a teologia da "medida por medida", cf. EGO, 2007, p. 141-154. 
Porém, se o povo de Israel receberia o perdão pela morte expiatória de seus mártires, através da mudança na história, o que os mártires receberiam, já que não estariam vivos para desfrutar das consequências deste perdão? Para os mártires de 2 Macabeus (pelo menos para os sete irmãos, em 2 Mac $7^{14}$ ), a entrega da vida pelo martírio tem como promessa futura a ressurreição, como está evidente na voz do segundo irmão torturado e morto por Antíoco: “Tu, celerado, nos tiras desta vida presente. Mas o Rei do mundo nos fará ressuscitar [ảv $\alpha \sigma \tau \eta ́ \sigma \varepsilon 1]^{15}$ para uma vida eterna ${ }^{16}$, a nós que morremos por suas leis!" (2 Mac 7.9). Deste modo, o desprezo ao corpo (encarando a morte), se dá pela "esperança de ser um dia ressuscitado" (2 Mac 7.14), ou seja, como esperança de se receber o corpo novamente (2 Mac 7.11) para uma "vida imperecível" (2 Mac 7.36), como retribuição divina (2 Mac 7.23) por sua misericórdia (2 Mac 7.29).

\section{A esperança na ressurreição}

Esta esperança na ressurreição, praticamente ausente na Bíblia Hebraica ${ }^{17}$, tem como grande ponto de partida o livro de Daniel (capítulo

14 Os martírios de Eleazar e Razis não fazem menção à crença na ressurreição, apesar de haver referência a uma esperança de volta do espírito (cf. 2 Mac 14.46b). Textos da Bíblia Hebraica contra a ressurreição: Jó 14.12; 26.5-6; 42.10; Is 26.14; Ec 9.5.

15 O termo àv $\alpha \sigma \tau \eta ́ \sigma \varepsilon ı$ pode designar tanto "ressuscitar" (como neste caso) como ainda "levantar" em sentido metafórico, cf. At 3.22; 7.37.

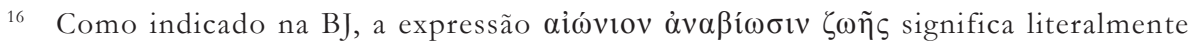
"revivificação eterna da vida". Esta expressão é teologicamente importante, uma vez que antes do desenvolvimento de uma teologia da ressurreição, havia relatos de vivificação, ou seja, ressurreições para esta vida, e não para uma vida eterna, a exemplo dos milagres efetuados por Elias (1 Rs 17) e Eliseu (2 Rs 4; 13.21). Outro exemplo (posterior) é a ressurreição de Lázaro (Jo 11). Sobre estes casos e o desenvolvimento da ideia de ressurreição, cf. VERMES, 2013, p. 42-43; MARTIN-ACHARD, 2015, p. 76-79; WRIGHT, 2003, p. 85-128.

17 Como lembra Geza Vermes, "na Bíblia Hebraica a ressurreição aparece pela primeira vez como metáfora, simbolizando o renascimento de uma nação" (VERMES, 2013, p. 14), tal como no livro de Ezequiel (37.1-14). Cf. LEVENSON, 2006; Os 6.1-3. A ressurreição somente aparece sendo afirmada no livro de Daniel (12.1-2), diferente de Isaías (26.19) que a sugere. Cf. MARTIN-ACHARD, 2015, p. 157-158; BRETTLER, 2002, p. 15. É claro que há interpretações a posteriori que encontram diversas referências da ressurreição na BH, até mesmo na Torá. Segundo o Middrash Sifre Devarim (3.2), por exemplo, "não falta a ressurreição dos mortos em nenhuma passagem, mas nos falta a capacidade de interpretar propriamente". A este respeito, cf. LEVENSON, 2006, p. 23-34. Sobre o desenvolvimento de uma teologia da ressurreição no Antigo Testamento, cf. MARTIN-ACHARD, 2015 [esp., p. 93-203]; VERMES, 2013, p. 21-47. 
12) ${ }^{18}$, o que é bastante sugestivo, uma vez que este livro, além de ter sido composto durante o período dos macabeus ${ }^{19}$, também carrega consigo elementos da teologia do martírio. Ainda que, segundo o relato, Daniel, Hananias, Misael e Azarias não tenham sido mortos, tiveram a coragem de mártires, enfrentando as decisões reais a fim de se manterem firmes em sua fé, estando dispostos a morrerem por esta: enquanto Daniel foi largado na cova dos leões por Dario em decorrência de ter buscado a seu Deus em oração (Dn 6) ${ }^{20}$, seus três amigos foram jogados na fornalha ardente por não adorarem a imagem de ouro de Nabucodonosor (Dn 3$)^{21}$.

Observando a presença do martírio e da ressurreição, tanto em Daniel como em 2 Macabeus, se pode perceber que "existe uma estreita relação entre o martírio e a ressurreição”, como indicou Robert Martin-Achard

18 "Multidões que dormem no pó da terra acordarão: uns para a vida eterna, outros para a vergonha, para o desprezo eterno. Aqueles que são sábios reluzirão como o brilho do céu, e aqueles que conduzem muitos à justiça serão como as estrelas, para todo o sempre" (Dn 12.2-3, NVI).

19 Segundo André L. Chevitarese, enquanto a primeira parte do livro (caps. 1-6) data entre 250 e 230 a.C., a segunda parte (caps. 7-12) pode ser datada entre 167 e 164 a.C., com bastante precisão (CHEVITARESE, 2004, p. 163). A diferença marcante entre as duas partes faz com que muitos autores indiquem uma datação mais antiga para a primeira parte (P. R. Davies, J. J. Collins, A. R. Millard), que poderia ainda ter sido composta posteriormente, antes do período macabeu (E. J. Bickerman). Contra: H. H. Rowley (defendeu a unidade do livro como composição macabeia). De toda forma, a tendência atual é indicar a composição final do livro durante a Revolta dos Macabeus, uma vez que a imposição da "abominação desoladora" (167 a.C.) é mencionada, mas a purificação do Templo (164 a.C.) não. Cf. DAVIES, 2001, p. 563-571 [563]; MILLAR, 2006, p. 57; MARTIN-ACHARD, 2015, p. 156; VERMES, 2013, p. 52; COLLINS, 1984, p. 101. Segundo Fergus Millar, "nenhum comentarista sério questionaria a demonstração de Porfírio que o trabalho pertence aos anos 160 sob Antíoco IV Epifânio, e que por isso e incluindo este ponto, as profecias neste são pseudo-profecias, relacionadas e dando sentido aos eventos que já ocorreram" (MILLAR, 2006, p. 57).

20 Daniel não ficou tão conhecido nos círculos judaicos como outros personagens, a exemplo de Noé e Jó (COLLINS, 1999, p. 219-220 [220]), mas ganha certa projeção em determinados contextos, a exemplo de Qumran. Cf. ULRICH, 2000, p. 170-174 [esp. 174]. Possivelmente a fama limitada se deu em decorrência de seu livro ser bastante posterior aos demais.

21 Apesar de não serem mencionados em $2 \mathrm{Mac}$, os três jovens são referidos em $1 \mathrm{Mac}$ 2.59-60, assim como são relacionados aos mártires de 2 Mac nos livros de 3 Mac e 4 Mac: em 3 Mac, Eleazar se refere a eles em sua oração (3 Mac 6.6), enquanto que em 4 Mac a morte dos sete irmãos é vista como uma mimesis da morte dos "três jovens [as]sírios que desprezaram uma ordem civil similar na fornalha” (4 Mac 13.9). Também Daniel e Misael são mencionados nos discursos dos irmãos e da mãe (4 Mac 13.3; 16.3,20). Cf. BASLEZ, 2007, p. 114. 
(2015, p. 238). De fato, teologicamente, “a ressurreição aparece como a resposta de Deus àquele que sacrifica tudo para ser-lhe fiel", ou seja, "a ressurreição é, de certa forma, a consequência do martírio, a recompensa do que aceita perder a vida por Yahweh" (MARTIN-ACHARD, 2015, p. 239), aquele que criou a vida e pode dá-la novamente ${ }^{22}$. Tanto o martírio como a ressurreição, sua consequência, aparecem timidamente na Bíblia Hebraica, mas acabam ganhando projeção no judaísmo do período helenístico, que começa a identificar elementos martiriológicos na Bíblia Hebraica, que passa a ser reinterpretada e vista sob uma nova luz ${ }^{23}$.

Apesar de não terem um completo fundamento na Bíblia Hebraica, as teologias do martírio e da ressurreição ganham força ao longo do período do Segundo Templo, como se pode perceber nas referências de Filo ${ }^{24}$ e de

22 Cf. 2 Mac 7.22-23,28-29. Sobre estes textos, G. W. E. Nickelsburg comenta: "Deus vai curar o que Antíoco feriu; ele vai trazer à vida quem Antíoco matou. O que Deus criou, Deus vai recriar - a despeito da tentativa do rei de destruir" (NICKELSBURG, 2006, p. 121). Isto significa que a ressurreição, diferente da crença grega na imortalidade da alma, depende da ação divina e não da natureza humana (cf. RUPPENTHAL NETO, 2015, p. 59). Diferente da psykhé ( $(\cup \chi \dot{\eta})$ grega, tomada no contexto helenístico como imortal, a nefesh (שפכָ hebraica, usualmente traduzida como "alma", ou "vida", não possuindo existência após a morte, depende de Deus que "lhe ajuda, perdoa e fortalece" (LYS, 1966, p. 183). A ressurreição, portanto, implica em uma "recriação" do ser humano, e é, segundo os rabinos, "tão admissível quanto a criação" (MARTIN-ACHARD, 2015, p. 246, nota 490). Cf. BARRETT, 1965, p. 101; LYS, 1966, p. 183. Sobre o conceito grego de psykhé, cf. RUPPENTHAL NETO, 2014. Sobre o conceito judaico de nefesh, cf. WOLFF, 2008, p. 33-56; RUPPENTHAL NETO, 2015; RUPPENTHAL NETO, 2016b. A respeito da diferença entre as concepções grega de imortalidade da alma e judaica de ressurreição, cf. CULLMANN, 2000; MIGLIORI, 2005; BARRETT, 1965 (contra). Sobre as diferenças entre nefesh e psykhé (esp. na LXX), cf. LYS, 1966; GONÇALVES, 2014.

23 A respeito dos casos de martírio na BH, cf. BRETTLER, 2002. Como bem lembra Robert Martin-Achard: "Abel é o tipo perfeito de mártir, a primeira testemunha morta por sua fé. Moisés, segundo algumas tradições palestinenses, deve voltar a esta terra para sofrer. Elias e Enoque deverão sofrer martírio e pelo seu sangue aniquilar o poder demoníaco. Isaías, segundo a Ascenção de Isaías, [foi] serrado em um tronco baixo (Hb 11.36)" (MARTIN-ACHARD, 2015, p. 239, nota 479). No NT as perseguições sofridas são retomadas inúmeras vezes: cf. Mt 23.31ss; At 7.52; Hb 11.36ss; 1 Ts 2.15; Ap 20.4ss. Também surgem outras figuras proféticas, paralelas à $\mathrm{BH}$, no qual se indica o martírio, a exemplo do profeta Zacarias, mencionado em Mt 23.34ss e que também aparece na literatura rabínica. Cf. BLANK, 1937-1938.

24 Filo, Quod Omn., 13.88-91; Leg., 233-236. Texto e comentário: VAN HENTEN; AVEMARIE, 2002, p. 76-79. 
Josefo $^{25}$, assim como nos Manuscritos de Qumran ${ }^{26}$, e mesmo na literatura
rabínica $^{27}$. No caso de Josefo, por exemplo, este chega a afirmar que "é um

25 Sobre a relação de Josefo com o martírio, cf. VERMES, 2013, p. 56; RAJAK, 2001, p. 124-126; VAN HENTEN; AVEMARIE, 2002, p. 83-87. Esp.: WEITZMAN, 2004; VAN HENTEN, 2007, p. 195-218 (esp. p. 197-199, lista com 51 passagens de Josefo com elementos da "morte nobre"). Quanto à ressurreição, a forma com que Josefo se refere à crença farisaica na vida após a morte na qual a "alma" revive em outro corpo (cf. $A J$, 18.14; BJ, 2.163) parece mais com a ideia de reencarnação, cf. ELLEDGE, 2006, p. 38; esp. DOBRORUKA, 2005; Josefo, Ap., 2.217-218. É provável, porém, que estivesse se referindo à ideia da ressurreição, defendida pelos fariseus (cf. Hipólito, Philos., 9.27), adaptando-a à linguagem e concepções do seu público grego. Cf. SCHUBERT, 1979, p. 12; VERMES, 2013, p. 63 (levanta a questão - Josefo ou Hipólito?). Sobre Josefo e a ressurreição, cf. WRIGHT, 2003, p. 175-181.

26 Apesar das referências à ressurreição em Psendo-Ezequiel (a: 4Q385, 2; b: 4Q386, 1-2) e no Apocalipse Messiânico (4Q521, 2.2.12; 5.2.5-6), assim como do amplo uso de 1 Enoque e Daniel, não está claro se de fato a Comunidade de Qumran defendia a ressurreição dos mortos. Cabe lembrar que, segundo Josefo $(A J, 18.18)$, os essênios acreditavam na imotalidade da alma. Apesar de Émile Puech ter indicado a crença na ressurreição como sendo atestada e aludida em diversos textos, J. J. Collins contestou seu método interpretativo. Cf. PUECH, 1993; COLLINS, 1997, p. 110-129. Para outros estudos da ressurreição em Qumran, cf. WRIGHT, 2003, p. 181-189; NICKELSBURG, 2000, p. 764-767 (II); HOBBINS, 2001, p. 385-420 (analisa a ressurreição em Daniel e outros textos de Qumran); COLLINS, 2006, p. 35-53 (interpreta a crença pós-morte de Qumran como imortalidade da alma); BROOKE, 2006, p. 15-33 (percebe a ideia de ressurreição em $1 \mathrm{QH}^{\mathrm{a}}$, 12.15-13.4).

27 Para os textos rabínicos que tratam da "morte nobre" e do martírio, cf. VAN HENTEN; AVEMARIE, 2002, p. 132-176. Quanto à ideia de ressurreição, cf. m. Sanh 10.1,3; m.

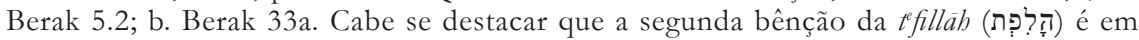
agradecimento pela ressurreição futura. Não está clara, porém, qual a extensão da crença na ressurreição pelos judeus antes de 70 d.C., quando os herdeiros rabinos dos fariseus se constituem como principal grupo judaico. De fato, Flávio Josefo, convertido ao farisaísmo (Vit., 1-12), lembra que outro grupo, dos saduceus, não acreditava na ressurreição: Josefo, AJ, 18.16; BJ, 2.16. Cf. Mt 22.23; Mc 12.18; Lc 20.27; At 23.8. Se considerar-se que a ressurreição era particular dos fariseus (em oposição aos saduceus), boa parte da população judaica, sendo gente simples do campo, poderia não seguir tal crença, por falta de contato ou mesmo por descrença. Assim, apesar de algumas inscrições funerárias judaicas do período trazerem afirmações da ressurreição como "ela viverá outra vez e outra vez retornará à luz" (Rursum victura reditura ad lumina rursum, CIJ 476, cf. VAN DER HORST, 1991, p. 112), há também outras que indicam ceticismo em relação à mesma: "Nenhum ser humano se levanta [do túmulo]; nem Eleazar ou Safira" (Rahmani no 455); "Amigos, eu espero por vocês aqui" (Amici ego vos hic expecto, CIJ 32); e, principalmente: "Boa sorte com sua ressurreição" (cf. VERMES, 2013, p. 73-74). A respeito dos epifáfios judaios relativos à morte e pós-morte, cf. VAN DER HORST, 1991, p. 114-126; PUECH, 1993, p. 182-199 (I). N. T. Wright defende que "a ressurreição não era simplesmente uma doutrina dos fariseus e dos sucessores putativos, os rabbis", mas antes "era amplamente crida pela maioria dos judeus por volta da virada da Era Comum" (WRIGHT, 2003, p. 147). Geza Vermes, no entanto, indica que "a noção de ressurreição corpórea propagada pelos fariseus era estranha aos judeus helenísticos do século I, e era totalmente desconhecida na maior parte das camadas dos judeus palestinos" (VERMES, 2013, p. 75). Para outras afirmações da ressurreição, cf. 1En 102-104; SISl 3.15; 4 Ed 5.41; TP: Levi 18, Judá 25, Benjamin 10. Contra: Tb 4.10; 13.2; Bar 2.17; 4.1; 1 Mac 2.49-70; Eclo 14.16ss; 38.21; 41.4. 
instinto em todo judeu, do dia do seu nascimento, respeitar [as Escrituras] como decretos de Deus, permanecer neles, e, se necessário, alegremente morrer por eles" (Ap., 1.43), de modo que "várias vezes, antes e agora, a [sua] visão foi testemunha de prisioneiros suportando torturas e morte de todas as formas nos teatros, ao invés de proferir uma única palavra contra a Lei e os documentos relacionados" (Ap., 1.43). Também dá exemplos de martírio nos seus relatos a respeito dos casos de Judas e Matias (BJ, 1.650), quando fala dos essênios (BJ, 2.152-153), e, principalmente, quando conta a respeito do suicídio coletivo realizado em Massada (BJ, 7.343).

Ao longo da história judaica, porém, a teologia do martírio ganhou novos encaminhamentos: começa a se delinear, com o tempo, a ideia da "santificação do nome" de Deus, Kiddûsh ha-Shem ${ }^{28}$, que não somente incorporou como também passou a ser definida pela lógica do martírio especialmente a partir da Idade Média, com as $\operatorname{cruzadas}^{29}$-, delineando não somente a ideia que os judeus tinham sobre o mesmo, como ainda acabou estabelecendo uma denominação própria para os "mártires" judeus, chamados de kedoshim (RAJAK, 2001, p. 102) 30 " "santos".

Apesar de aparentemente este novo uso do termo kedoshîm datar do período da perseguição romana de Adriano (cf. HOLTZ, 1961, p. 367, nota

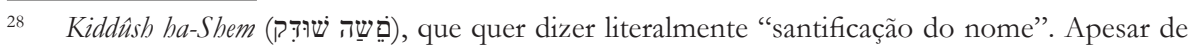
originalmente a expressão designar o temor a Deus, mediante o respeito pelo seu santuário, mandamentos e sacerdotes (cf. Nm 20.12; Dt 32.51), passou a ser compreendido como designação do martírio pelo judaísmo, no caso de evitar pecar por idolatria, fornicação e assassinato (Sanh 74a), em tempos normais, ou ainda por qualquer pecado, em tempos de perseguição (t. AvZar 27b). O sentido original pode ser percebido Siddur, cf. HOLTZ, 1964. Para o novo significado, cf. TgNeof sobre Gn 38.25-26. Da mesma forma seu

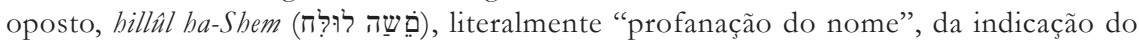
desrespeito às coisas sagradas, passou a designar o comportamento que traz descrédito dos judeus aos gentios, assim como a falta em relação ao martírio (cf. t. AvZar 27b; Sanh 74a-b). Cf. MACCOBY, 1984/1985; BEN SASSON, 2007, p. 977-986 (X); BRETTLER, 2002, p. 3-4; VAN HENTEN, 1997, p. 304.

29 A respeito da relação entre os judeus e a Primeira Cruzada (1096), cf. CHAZAN, 1996; COHEN, 2013. Para as narrativas judaicas a respeito desta cruzada, cf. CHAZAN, 2000. Para os diversos relatos judaicos sobre as Cruzadas, cf. FALBEL, 2001. A respeito da situação dos judeus na Cristandade Medieval, cf. CHAZAN, 2006.

30 Enquanto a palavra "mártir" provém do grego mártys ( $\mu \dot{\alpha} \varrho \tau \varsigma \varsigma$ ), "testemunha”, tendo recebido nova significação na tradição critstã (cf. Mart. Polyc., 1.1; 2.1; 14.2), kedoshîm

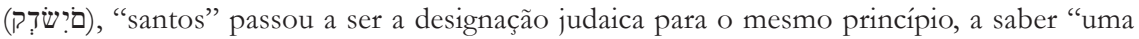
carta pessoa que em uma situação hostil extrema prefere uma morte violenta à submissão em relação a uma demanda das autoridades (normalmente pagãs)" (VAN HENTEN, 2005, p. 145 , nota 9). 
72), ganha especial importância na Idade Média, quando os judeus são "forçados a abraçar o cristianismo, ou o islamismo, mediante ameaças a suas vidas" (FALBEL, 2001, p. 272). Isto é especialmente evidente nos relatos judaicos a respeito das Cruzadas, nos quais as vítimas judaicas são percebidas como verdadeiros mártires.

Em 2 Macabeus, porém, séculos antes dos kedoshîm medievais, os mártires não seguiam uma lógica martirológica pré-estabelecida, nem uma tradição, mas se dispõem como meio de ligação entre Deus e seu povo, como sacrifício, estabelecendo uma ligação com o sistema sacrificial da Bíblia Hebraica $^{31}$, centrado no perdão e reconciliação por parte de Deus ${ }^{32}$.

\section{Ideologia da resistência}

Assim como a teologia da reconciliação faz com que o autor estabeleça um paralelo com a Bíblia Hebraica, um outro aspecto do livro, que é a ideologia da resistência, o faz colocar as Escrituras na boca do próprio Judas Macabeu. Afinal, a teologia da resistência, dentro deste contexto judaico, pode ser entendida como a afirmação da cultura e da religião judaicas a partir de uma oposição direta, de caráter político mas também cultural, aos poderes estrangeiros dominantes que, tanto no caso do Império Ptolomaico - do contexto anterior a 2 Macabeus -, quanto do Império Selêucida - deste contexto -, ou ainda no caso do Império Romano - no contexto posterior -, foram marcados pela cultura helenística, de modo que "esta cultura era um instrumento de três impérios sucessivos” (RAJAK, 2001, p. 3) que dominaram os judeus, fazendo com que, por oposição à cultura grega, própria do poder dominante, a cultura judaica se apresenta-se como uma forma de resistência. Neste sentido, o líder da Revolta dos Macabeus torna-se não somente o líder político dos judeus, mas também seu representante em uma resistência cultural cujo valor ultrapassa o evento descrito. Colocar as Escrituras na boca de Judas Macabeu, portanto, serve como uma forma de legitimação, por meio da religião judaica, da ideologia de resistência.

Deste modo, antes de enfrentar Nicanor, Judas relembra seus soldados sobre o auxílio divino na luta contra Senaqueribe (2 Mac 8.19), assim como

\footnotetext{
31 A relação entre martírio e sacrifício é utilizada posteriormente, no cristianismo, cf. Mart. Polyc. 14; Vita Polyc. 6. É uma inovação de 2 Macabeus, porém, para o contexto judaico, ficando particularmente evidente no suicídio de Razis como uma espécie de sacrifício de si mesmo. Cf. RUPPENTHAL NETO, 2018.

32 Cf. ROMEROWSKI, 2006.
} 
pede a Esdras que leia o "livro santo" 33 antes de dar sua palavra de ordem para a batalha ${ }^{34}$ : "auxílio de Deus" (2 Mac 8.23) 35. As Escrituras, portanto, servem como eco especial para o encorajamento dos soldados. Os corajosos não são exaltados por uma bravura cega, mas antes por uma decisão consciente: encorajando-os para a batalha contra Nicanor, Judas lhes dá bravura de forma que estão "prontos a morrerem pelas leis e pela pátria" (2 Mac 8.21), conscientes da "multidão enorme de pagãos que injustamente vinham atacá-los" (2 Mac 8.16) e estando em contraste com "os que ficaram com medo e não confiavam na justiça de Deus", e que por isso "fugiram para se porem a salvo e abandonaram o seu posto" (2 Mac 8.13). Assim sendo,

33 Como bem destacado por Pieter W. Van der Horst, diferente de 1 Mac 3.48, onde se fala que os judeus consultaram o "livro da Lei" ( à Torá-, em 2 Mac 8.23 fala-se no "livro santo" (

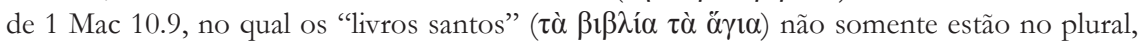

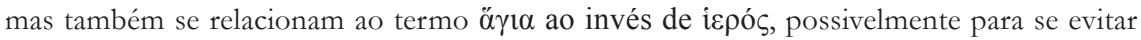
a relação com o sentido cúltico grego (BREMMER, 2010, p. 399). Muito próximo de 2 Mac 8.23 é o uso feito por Alexandre Polihistor (FGrH 273 F $19.29=$ Eusébio, Praep. evang., 9.29.1,15). Apesar de a Torá ser designada por termos semelhantes na Carta de

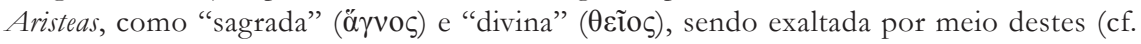
CArist, 3,5,31,45), 2 Mac 8.23 pode ser uma referência a um cânon mais amplo, incluindo (mesmo que parcialmente) os Profetas e os Escritos. Contra: BREMMER, 2010, p. 338. Seguindo esta mesma perspectiva, Christian Habicht (1976, p. 241, nota a) indica a "ajuda

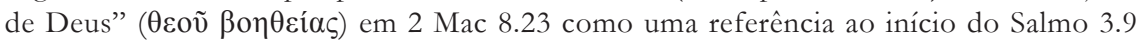

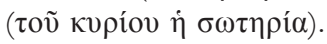

34 Parece que, assim como os pagãos ofereciam sacrifícios (cf. JAMESON, 1991, p. 197227) e consultavam seus deuses pelos arúspices antes das batalhas, os judeus passaram a consultar a Deus por meio do texto sagrado (cf. 1 Mac 3.48). Segundo Van der Horst, apesar da prática judaica da sortes biblicae (consultar textos sagrados aleatoriamente) só ser atestada posteriormente na literatura rabínica de outras formas, o contexto grego abre esta possibilidade, por apresentar diversos exemplos, cf. VAN DER HORST, 2000; VAN DER HORST, 1998, p. 143-173. Cabe se destacar que desde tempos remotos os judeus possuíam meios para consultar a Deus, tais como o 'Urym e o Tumym (םימתו םירוא), com os quais se buscava a vontade divina por meio da sorte (cf. Êx 28.30; Lv 8.8; Nm 27.21; Dt 33.8; 1 Sm 28.6; Ed 2.63; Ne 7.65). Sobre o 'Urym e o Tumym, cf. ROBERTSON, 1964; LIPIŃSKI, 1970; HOUTMAN, 1990 [refs. na ordem do debate].

35 Jonathan A. Goldstein (1983, p. 335) lembra que gregos e romanos também se valeram de palavras de ordem antes das batalhas (gritos de guerra?), cf. Xenofonte, An., 1.8.17; Apiano, $B C, 2.11 .76$. Cabe destacar que a expressão "ajuda de Deus", que aparece em 2 Mac 8.23 (em grego: $\theta \varepsilon$ õ $\beta$ oך $\theta \varepsilon i ́ \alpha \varsigma$ ), também aparece nos estandartes da Comunidade de Qumran, segundo o Ms. 1QM (col. IV, em aramaico): “Quando eles retornarem da batalha devem escrever em seus estandartes: Salvação de Deus, Vitória de Deus, Ajuda de Deus, Suporte de Deus, Alegria de Deus, Ações de graças de Deus, Louvor de Deus, Paz de Deus" (VERMES, 1980, p. 129). Cf. VAN DER HORST, 2000, p. 12, nota 12. 
se, por um lado, os mártires são exaltados em 2 Macabeus como heróis do relato, por outro também o são os combatentes da Revolta, destacados por sua bravura na luta de resistência.

\section{A bravura como elemento ideológico}

A bravura dos soldados também é destacada pelo tamanho do inimigo a ser enfrentado. Como indicado anteriormente (1.1.2.), a Revolta dos Macabeus se estabeleceu como uma guerrilha, compensando o pequeno número de tropas com suas táticas. Apesar que, de fato, seja muito provável que os selêucidas possuíssem um número consideravelmente maior de tropas ${ }^{36}$ e armas melhores à disposição, os livros de 1 e 2 Macabeus claramente construíram uma imagem onde a diferença de forças é destacada, enfatizando o aspecto heroico das mesmas. Se em 1 Macabeus o relato apresenta as forças

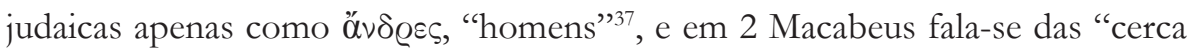
de seis mil pessoas" (2 Mac 8.1) que se juntam à causa, ambos os relatos fazem descrições "ricas em detalhes" dos exércitos inimigos (BAR-KOCHVA, 1989, p. 68): fala-se dos seus números, seus armamentos, e, principalmente,

36 Apesar do número indicado em 1 Macabeus 6.30 e 9.4 ser um tanto quanto exagerado, é difícil de se pensar que o exército rebelde fosse maior que o exército imperial. Em busca de uma indicação numérica, Bezalel Bar-Kochva aponta que o número de 100.000 homens de infantaria, 20.000 cavaleiros e 32 elefantes, indicado em 1 Macabeus 6.30, ultrapassa a possibilidade de mobilização de tropas não somente das regiões ocidentais do Império Selêucida, mas também deste como um todo (BAR-KOCHVA, 1989, p. 40). Mais razoável é se pensar em cerca de 20.000 soldados e 2.000 cavaleiros (1 Mac 9.4), o que seria possível para algumas situações, levando-se em conta o que é registrado por Políbio (Hist., 5.79.13), o qual afirma que na batalha de Rafia teriam participado 68.000 soldados selêucidas (62.000 de infantaria e 6.000 cavaleiros), assim como o que registra Tito Lívio (Hist., 37.37.9), indicando que na batalha de Magnesia haveriam 72.000 soldados selêucidas (60.000 infantaria e 12.000 cavalaria). Para uma tabela a respeito dos números de tropas selêucidas, cf. BAR-KOCHVA, 1989, p. 34. As fontes judaicas (1 Mac, 2 Mac e Josefo), no entanto, divergem consideravelmente quanto ao número de soldados indicados, a exemplo da segunda expedição de Lísias, para a qual Josefo (BJ, 1.41) aponta 50.000 soldados e 5.000 cavaleiros, 1 Macabeus (6.30) fala de 100.000 homens de infantaria, 20.000 cavaleiros e 32 elefantes, e 2 Macabeus (13.2) indica 110.000 soldados, 5.300 cavaleiros, 22 elefantes e 300 carros armados de foices. Fica, portanto, evidente a dificuldade de se precisar números para os exércitos envolvidos na Revolta. Sobre o número de combatentes em ambos os lados, cf. BAR-KOCHVA, 1989, p. 29-67. Sobre o tamanho do exército selêucida, cf. BAR-KOCHVA, 1976, p. 7-19.

37 Cf. 1 Mac 4.6,29; 5.20; 7.40; 9.5. 
de seus elefantes de guerra, extraordinariamente presentes no imaginário a respeito do Império Selêucida ${ }^{38}$.

Assim, a simbologia do poderio bélico selêucida mediante os elefantes de guerra, é utilizada não somente por estes (como na escultura acima), mas também pelos próprios judeus (em 2 Macabeus). Afinal, a diferença de exércitos, em quantidade e armamentos, serviu para exaltar ainda mais a fama da valentia de Judas e de seus companheiros, que já se espalhava durante a própria revolta. Porém, esta exaltação tem seus limites: afinal, apesar da resistência ter um forte aspecto de heroísmo, exaltado por sua própria fraqueza, somente alcança a vitória por conta da assistência divina: Deus realiza intervenções ${ }^{39}$ e faz aparições celestes ${ }^{40}$, "enviadas para encorajar e ajudar os combatentes” (BERTHELOT, 2006, p. 107).

\section{Entre a ideologia e a teologia}

Deste modo, apesar da bravura de Judas e seus companheiros ser destacada no texto ${ }^{41}$, é minimizada (especialmente se comparado a 1 Macabeus) quando se atrai "a atenção do leitor à dimensão sobrenatural e miraculosa daquela guerra” (BERTHELOT, 2006, p. 107). Tal assistência divina, porém, é decorrente do martírio, de modo que não somente conecta as duas ideologias (martírio e resistência) como também indica o valor destas, o qual é sobrenatural.

Neste sentido, 2 Macabeus parece estar entre 1 Macabeus, onde o martírio é eclipsado pelo combate armado (BERTHELOT, 2006, p. 101;

\footnotetext{
38 Os elefantes, muito utilizados pelos selêucidas em guerras, se tornaram o símbolo do Império Selêucida, de modo que não somente aparecem em cunhagens de moedas (cf. HOUGHTON; LORBER; HOOVER, 2008, nº 21-22; 1084e; SPAER; HOUGHTON, 1998, n 188-192; 822-825; 1774-1776), mas também Seleuco I ficou conhecido como "mestre dos elefantes" e "o rei elefante". Não é à toa, portanto, a designação do Império Selêucida como a "terra dos reis elefantes", como no título da obra de Paul J. Kosmin (2014).

39 Cf. 2 Mac 8.20,23,35; 12.11; 13.13; 15.8.

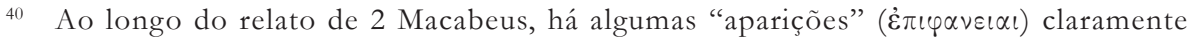
decorrentes da intervenção divina. Cf. 2 Mac 2.21; 3.24-30; 12.22; 14.15; 15.27,34. Nestes casos, há certa mistura de elementos judaicos e helenísticos, como se pode perceber no relato dos guerreiros divinos montados em cavalos e com armaduras douradas (cf. 2 Mac 3.25). Apesar da ideia de guerreiros divinos estar na literatura bíblica, geralmente aparecem com carros de fogo. Cf. 2 Rs 2; 6. A imagem de cavaleiros dourados, porém, parece estar mais relacionada com elementos da literatura grega, como indicou Robert Doran. Cf. DORAN, 1981, p. 98-103. Trata-se, portanto, de mais um elemento literário que indica a influência helenística na obra. Cf. HIMMELFARB, 1998, p. 30.

41 Cf. 2 Mac 2.19-22; 8.7; 13.14.
} 
RUPPENTHAL NETO, 2017, p. 77-82), e 4 Macabeus, onde o conflito militar não é mencionado, perdendo o lugar para o martírio, que ganha projeção. Haveria, assim, certo desenvolvimento da "Guerra Santa" (de 1 Macabeus) ao "Martírio Santo" (de 4 Macabeus), no qual 2 Macabeus teria aspectos de ambos elementos (BROWNLEE, 1983), porém, enfatizando o novo elemento, o martírio, que ganha destaque e evidência pela perspectiva sobrenatural do relato.

É por isso que, apesar de ambos elementos - martírio e resistência estarem presentes e terem importância no relato de 2 Macabeus, há "uma hierarquia clara, que coloca o martírio em primeiro lugar” (BERTHELOT, 2006, p. 110) em relação à resistência armada. Afinal, "a expiação não é realizada pelos guerreiros comandados por Judas; é o sangue dos mártires que faz a expiação por todo o povo" (HABICHT, 2006, p. 99), de certo modo "permitindo" a ação divina.

Não é à toa, portanto, que a ideologia da resistência armada possui tantos pontos em comum com a teologia do martírio, tais como o heroísmo, a disposição do sacrifício de si, e ainda a exigência de fidelidade à Lei. Afinal, como lembra Katell Berthelot (2006, p. 102), a ideologia da resistência armada "não é somente política, mas também intrinsecamente religiosa". Sendo assim, os aspectos ideológicos do livro de 2 Macabeus não são somente judaicos mas também intimamente relacionados ao próprio judaísmo, como realidade político-religiosa, mesmo que sua estrutura literária seja não apenas recheada como ainda formatada por elementos gregos.

\section{O livro de 2 Macabeus à luz do martírio e da resistência}

Deste modo, a configuração de 2 Macabeus se dá mediante uma aparente contradição: "é ao mesmo tempo judaica em sua piedade, e grega em seu modo de expressão", como indicou Martha Himmelfarb (1998, p. 20). Assim, se por um lado apresenta um aspecto ideológico completamente judaico - e até mesmo oposto à cultura grega, seu aspecto literário é carregado de elementos gregos ${ }^{42}$, dos quais o livro não pode (nem deve) ser desvinculado. Afinal, os elementos gregos em seu aspecto literário não são somente uma questão de forma, mas afetam também seu conteúdo.

\footnotetext{
Também Christian Habicht indicou esta contradição: "Do ponto de vista da história da teologia, o livro é puramente judaico; do ponto de vista da história da literatura, é primariamente grego" (HABICHT apud HIMMELFARB, 1998, p. 20). Sobre os elementos gregos em 2 Macabeus, cf. SIMKOVICH, 2011.
} 
Ultrapassam a linguagem, alcançando o método e até mesmo o estilo do livro. Não se trata, portanto, somente de necessidade por parte do autor, mas antes é resultado de uma verdadeira intencionalidade. Como lembra Himmelfarb, “a forma literária grega de 2 Macabeus representa mais que uma influência grega superficial” (HIMMELFARB, 1998, p. 20).

O livro de 2 Macabeus, portanto, em sua aparente contradição entre seus aspectos literário e ideológico, é um exemplo que vai contra sua própria intenção de separação absoluta entre judaísmo e helenismo, deixando claro o caráter artificial desta afirmação. É evidente, consequentemente, que a oposição entre helenismo e judaísmo que o livro de 2 Macabeus apresenta é muito mais uma construção ideológica do que uma realidade histórica. Cabe, por enquanto, a percepção de que a relação entre judaísmo e helenismo, refletida no estudo do livro, "é uma relação tanto mais complicada quanto mais cordial que a retórica de oposição que 2 Macabeus sugere" (HIMMELFARB, 1998, p. 20).

\section{Considerações finais}

Deste modo, se por um lado 2 Macabeus segue o cânon judaico, se aproximando da teologia do Antigo Testamento na intervenção divina na história do povo judeu e mesmo na teologia da reconciliação, por outro lado se coloca junto à historiografia grega, estabelecendo um relato não somente escrito em grego, mas também carregado da mentalidade grega e de formas literárias próprias da literatura helenística. É justamente esta particular mistura, quase contraditória, que faz de 2 Macabeus "algo único na historiografia antiga" (MOMIGLIANO, 1975, p. 81), e que torna a questão da relação entre helenismo e judaísmo, dentro do livro, tão importante do ponto de vista historiográfico. Por tal razão, são a teologia do martírio e a ideologia da resistência que deixam transparecer de forma mais clara e profunda a relação que o livro de 2 Macabeus estabelece com a religião e até mesmo com a cultura judaica. Demonstram, portanto, que, apesar do autor do livro ter uma vinculação evidente com a literatura helenística e a cultura grega daquele contexto, não deixa de ter um vínculo de enraizamento de suas ideias e perspectivas, sejam teológicas ou ideológicas, na tradição judaica, fazendo do livro de 2 Macabeus uma obra essencial para a compreensão do judaísmo helenístico que se desenvolve naquele contexto. 


\section{Referências}

BAR-KOCHVA, Bezalel. Judas Maccabaeus: The Jewish Struggle Against the Seleucids. Cambridge: Cambridge University Press, 1989.

BAR-KOCHVA, Bezalel. The Seleucid Army: Organization and Tactics in the Great Campaigns. Cambridge: Cambridge University Press, 1976. (Cambridge Classical Studies).

BARRETT, C. K. Immortality and Resurrection. London Quarterly \& Holborn Review, London, Vol. 190, p. 91-102, April 1965.

BASLEZ, Marie-Françoise. The Origin of the Martyrdom Images: From the Books of the Maccabees to the First Christians. In: XERAVITS, Géza G.; ZSENGELLÉR, Jószef (Ed.). The Books of the Maccabees: History, Theology, Ideology. Papers of the Second International Conference on the Deuterocanonical Books, Pápa, Hungary, 9-11 June, 2005. Leiden/Boston: Brill, 2007. p. 113-130.

BEN SASSON, H. H. Kiddush ha-Shem and Hillul ha-Shem. In: SKOLNIK, Fred (Ed.). Encyclopaedia Judaica. 2 ed. Detroit/Jerusalem: Thomson Gale; Keter Publishing House, 2007. 22 v. p. $977-986(\mathrm{X})$.

BERTHELOT, Katell. L’idéologie Maccabéenne: Entre Idéologie de la Résistance Armée et Idéologie du Martyre. Revue de Études Juives, Leuven, Vol. 165, No. 1-2, p. 99-122, janvier-juin 2006.

BICKERMAN, Elias J. Studies in Jewish and Christian History. A New Edition in English including The God of the Maccabees. Introduced by Martin Hengel. Edited by Amram Tropper. Leiden/Boston: Brill, 2007. (Ancient Judaism and Early Christianity, 68). 2 v.

[BJ] BÍBLIA DE JERUSALÉM. Tradução do texto em língua portuguesa diretamente dos originais sob a coordenação de Gilberto da Silva Gorgulho, Ivo Storniolo e Ana Flora Anderson. 9 reimpressão. São Paulo: Paulus, 2013.

BLANK, Sheldon H. The Death of Zechariah in Rabbinic Literature. Hebrew Union College Annual, Vol. 12/13, p. 327-346, 1937-1938.

BREMMER, Jan N. From Holy Books to Holy Bible: An Itinerary from Ancient Greece to Modern Islam via Second Temple Judaism and Early Christianity. In: POPOVIĆ, Mladen. (Ed.). Authoritative Scriptures in Ancient Judaism. Leiden: Martinus Nijhoff/Brill, 2010. (Supp JSJ, 141). p. 327-360.

BREMMER, Jan N. Scapegoats Rituals in Ancient Greece. Harvard Studies in Classical Philology, Cambridge, MA, Vol. 87, p. 299-320, 1983.

BRETTLER, Marc. Is there Martyrdom in the Hebrew Bible? In: CORMACK, Margaret. (Ed.). Sacrificing the Self: Perspectives on Martyrdom and Religion. Oxford: Oxford University Press, 2002. (American Academy of Religion, The Religions Series). p. 3-22.

BROOKE, George J. The Structure of 1Qha XII 5-XIII 4 and the meaning of Resurrection. In: GARCÍA MARTÍNEZ, Florentino; STEUDEL, Annette; TIGCHELAAR, Eibert. (Ed.). From 4QMMT to Resurrection: Mélanges qumraniens en hommage à Émile Puech. Leiden/Boston: Brill, 2006. (Studies on the texts of the Desert of Judah, 61). p. 15-33.

BROWNLEE, William H. From Holy War to Holy Martyrdom. In: HUFFMON, H. B.; SPINA, F. A.; GREEN, A. R. W. (Ed.). The Quest for the Kingdom of God: Studies in Honor of George E. Mendenhall. Winona Lake: Eisenbrauns, 1983. p. 281-292. 
CHAZAN, Robert. God, Humanity, and History: The Hebrew First Crusade Narratives. Berkeley/Los Angeles/London: University of California Press, 2000. (The S. Mark Taper Foundation Imprint in Jewish Studies).

CHAZAN, Robert. In the Year 1096: The First Crusade and the Jews. Philadelphia/Jerusalem: The Jewish Publication Society, 1996 (5755).

CHAZAN, Robert. The Jews of Medieval Western Christendom, 1000-1500. Cambridge: Cambridge University Press, 2006.

CHEVITARESE, André L. Judaísmo e helenismo: Reflexões em torno de Daniel 9,1-19. Dimensões, Vitória, Vol. 16, p. 161-171, 2004.

CIAMPA, Roy E. The Presence and Function of Scripture in Galatians 1 and 2. Tübingen: Mohr Siebeck, 1998. (Wissenschaftliche Untersuchungen zum Neuen Testament, 2. Reihe, 102).

COHEN, Jeremy. Sanctifying the Name of God: Jewish Martyrs and Jewish Memories of the First Crusade. Philadelphia: University of Pennsylvania Press, 2013.

COLLINS, John J. Apocalypticism in the Dead Sea Scrolls. London/New York: Routledge, 1997. (The Dead Sea Scrolls).

COLLINS, John J. Daniel. In: VAN DER TOORN, Karel; BECKING, Bob; VAN DER HORST, Pieter W. (Ed.). Dictionary of Deities and Demons in the Bible: (DDD). Second Extensively Revised Edition. Leiden/Boston/Köln/Michigan: Brill/Eerdmans, 1999. p. 219-220.

COLLINS, John J. Daniel: with an Introduction to Apocalypse Literature. Grand Rapids: Eerdmans, 1984. (The Forms of the Old Testament Literature, 20).

COLLINS, John J. The Essenes and the Afterlife. In: GARCÍA MARTÍNEZ, Florentino; STEUDEL, Annette; TIGCHELAAR, Eibert. (Ed.). From 4QMMT to Resurrection: Mélanges qumraniens en hommage à Émile Puech. Leiden/Boston: Brill, 2006. (Studies on the texts of the Desert of Judah, 61). p. 35-53.

CULLMANN, Oscar. Immortality of the Soul or Resurrection of the Dead? The Witness of the New Testament. Eugene: Wipf \& Stock, 2000.

DAVIES, P. R. Daniel. In: BARTON, John Barton; MUDDIMAN, John (Ed.). The Oxford Bible Commentary. Oxford: Oxford University Press, 2001.. p. 563-578.

DE ROO, Jacqueline C. R. Was the Goat for Azazel destined for the Wrath of God? Biblica, Roma, Vol. 81, p. 233-242, 2000.

DESILVA, David Arthur. 4 Maccabees: Introduction and Commentary on the Greek Text in the Codex Sinaiticus. Leiden/Boston: Brill, 2006. (Septuagint Commentary Series).

DOBRORUKA, Vicente. Reencarnação e o judaísmo de Flávio Josefo como instrumentos hermenêuticos para entender a pseudepigrafia apocalíptica. Oracula, São Bernardo do Campo, Vol. 1, No. 2, p. 20-26, 2005.

DORAN, Robert. Temple Propaganda: The Purpose and Character of 2 Maccabees. Washington: The Catholic Biblical Association, 1981. (The Catholic Biblical Quarterly Monograph Series, 12).

DOUGLAS, Mary. The Go-Away Goat. In: RENDTORFF, Rolf; KLUGER, Robert A. (Ed.). The Book of Leviticus: Composition and Reception. With the Assistance of Sarah Smith Bartel. Leiden/Boston: Brill, 2003. (Supp VT, 93). p. 121-141. 
EGO, Beate. God's Justice: The "Measure for Measure" Principle in 2 Maccabees. In: XERAVITS, Géza G.; ZSENGELLÉR, Jószef (Ed.). The Books of the Maccabees: History, Theology, Ideology. Papers of the Second International Conference on the Deuterocanonical Books, Pápa, Hungary, 9-11 June, 2005. Leiden/Boston: Brill, 2007. p. 141-154.

ELLEDGE, C. D. Resurrection of the Dead: Exploring Our Earliest Evidence Today. In: CHARLESWORTH, James H. et al (Ed.). Resurrection: The Origin and Future of a Biblical Doctrine. New York: T \& T Clark, 2006. (Faith and Scholarship Colloquies Series). p. 22-52.

FALBEL, Nachman. Kidush HaShem: Crônicas Hebraicas sobre as Cruzadas. São Paulo: Editora da Universidade de São Paulo; Imprensa Oficial do Estado, 2001.

FEINBERG, Charles L. The Scapegoat of Leviticus Sixteen. Bibliotheca Sacra, Dallas, Vol. 115, p. 320-333, 1958.

GONÇALVES, Alex Fabiano Campos. Psykhé e néfesh: um estudo comparativo da tradução de néphesh por psykhé em alguns versículos na Septuaginta. Coletânea, Rio de Janeiro, Ano XIII, Fasc. 25, p. 160-172, Jan./Jun. 2015.

HABICHT, Christian. 2 Makkabäerbuch. Gütersloh: Gütersloher, 1976. (Jüdische Schriften aus hellenistisch-römischer Zeit, 1.3).

HABICHT, Christian. The Hellenistic Monarchies: Selected Papers. Ann Arbor: The University of Michigan Press, 2006.

HEARD JR., Warren Joel. Maccabean Martyr Theology: Its Genesis, Antecedents and Significance for the Earliest Soteriological Interpretation of the Death of Jesus. 1987. 588 f. Ph.D. Thesis University of Aberdeen, Aberdeen, 1989.

HIMmelfarB, Martha. Judaism and Hellenism in 2 Maccabees. Poetics Today, Vol. 19, No. 1, p. 19-40, Spring 1998.

HOLTZ, Avraham. Kiddush and Hillul Hashem. Judaism, Vol. 10, No. 4, p. 360-367, 1961.

HOUGHTON, Arthur A. LORBER, Catherine C.; HOOVER, Oliver D. Seleucid Coins, A Comprehensive Guide. New York: American Numismatic Society, 2008. Part 2: Seleucus IV through Antiochus XIII.

HOUTMAN, C. The Urim and Thummim: A New Suggestion. Vetus Testamentum, Leiden, Vol. 40, Fasc. 2, p. 229-232, Apr. 1990.

JAMESON, Michael H. Sacrifice before battle. In: HANSON, Victor Davis (Ed.). Hoplites: The Classical Greek Battle Experience. London: Routledge, 1991. p. 197-227.

KOSMIN, Paul J. The Land of the Elephant Kings: Space, Territory, and Ideology in the Seleucid Empire. Cambridge, MA/London: Harvard University Press, 2014.

LEVENSON, Jon D. Resurrection and the Restoration of Israel: The Ultimate Victory of the God of Life. New Haven \& London: Yale University Press, 2006.

LIPIŃSKI, E. 'Ūrīm and Tummīm. Vetus Testamentum, Leiden, Vol. 20, Fasc. 4, p. 495-496, Oct. 1970.

LYS, Daniel. The Israelite Soul According to the LXX. Vetus Testamentum, Leiden, Vol. 16, Fasc. 2, p. 181-228, Apr. 1966. 
MACCOBY, Hyam. Kiddush ha-Shem. European Judaism: A Journal for the New Europe, Vol. 18, No. 1, p. 31-34, Winter 1984/1985.

שיאית:ע (Leviticus 16:21): A Marginal Person. Journal of Biblical Literature, Atlanta, GA, Vol. 128, No. 3, 2009. p. 437-442.

MARTIN-ACHARD, Robert. Da morte à ressurreição segundo o Antigo Testamento. Santo André: Academia Cristã, 2015.

MCCLELLAN, Daniel O. A Reevaluation of the Structure and Function of 2 Maccabees 7 and its Text-Critical Implications. Studia Antiqua, Vol. 7, No. 1, p. 82-95, Spring 2009.

MIGLIORI, Maurizio. La domanda sull'immortalità e la resurrezione: paradigma greco e paradigma biblico. Hypnos, São Paulo, Ano 10, No. 14, p. 1-23, $1^{\circ}$ Sem. 2005.

MILLAR, Fergus. Hellenistic History in a Near Eastern Perspective: The Book of Daniel. In: MILLAR, Fergus. Rome, the Greek World, and the East. Volume 3: The Greek World, the Jews, and the East. Edited by Hannah M. Cotton and Guy M. Rogers. Chapel Hill: The University of North Carolina Press, 2006. p. 51-66.

MOMigliAnO, Arnaldo. The Second Book of the Maccabees. Classical Philology, Chicago, Vol. LXX, Number 2, p. 81-88, April 1975.

NICKELSBURG, George W. E. Ancient Judaism and Christianity: Diversity, Continuity, and Transformation. Minneapolis: Fortress Press, 2003.

NICKELSBURG, George W. E. Resurrection. In: SCHIFFMAN, Lawrence H. Schiffman; VANDERKAM, James C. (Ed.). Encyclopedia of the Dead Sea Scrolls. Oxford: Oxford University Press, 2000. 2 v. p. 764-767 (II).

NICKELSBURG, George W. E. Resurrection, Immortality, and Eternal Life in Intertestamental Judaism and Early Christianity. Cambridge, MA: Harvard University Press, 2006. (Harvard Theological Studies, 56).

PUECH, Émile. La croyance des Esséniens en la vie future. 2 Volumes. Paris: Lecoffre, 1993. (Études bibliques, 21-22).

RAJAK, Tessa. The Jewish Dialogue with Greece and Rome: Studies in Cultural and Social Interaction. Leiden/Boston/Köln: Brill, 2001. (Arbeiten zur Geschichte des Antiken Judentums und des Urchristentums, 48).

ROBERTSON, Edward. The 'Ūrīm and Tummīm; What Were They? Vetus Testamentum, Leiden, Vol. 14, Fasc. 1, p. 67-74, Jan. 1964.

ROMEROWSKI, Sylvain. Old Testament Sacrifices and Reconciliation. European Journal of Theology, Vol. 16, No. 1, p. 13-24, 2006.

RUPPENTHAL NETO, Willibaldo. A psykhé entre os gregos: do mito homérico às concepções pré-socráticas. 2014. 67 f. Trabalho de Conclusão de Curso (Licenciatura em História) - Universidade Federal do Paraná, Curitiba, 2014.

RUPPENTHAL NETO, Willibaldo. As interpretações de Azazel em Levítico 16. Ensaios Teológicos, Ijuí, Vol. 2, No. 1, p. 11-29, 2016a.

RUPPENTHAL NETO, Willibaldo. Introdução à teologia de 1 Macabeus. Teologia e Espiritua- 
lidade, Curitiba, Vol. 4, No. 7, p. 71-90, Junho 2017.

RUPPENTHAL NETO, Willibaldo. O conceito de nefesh no Antigo Testamento. Vox Scripturae Revista Internacional de Teologia, São Bento do Sul, Vol. 24, No. 1, p. 31-53, 2016 b.

RUPPENTHAL NETO, Willibaldo. O ser humano necessitado: as implicações do conceito de nefesh nas ideias de homem, vida e morte na antropologia do Antigo Testamento. 80 f. Trabalho de Conclusão de Curso (Bacharelado em Teologia) - Faculdades Batista do Paraná, Curitiba, 2015.

RUPPENTHAL NETO, Willibaldo. Violência contra si como sacrifício: o suicídio de Razis em 2 Macabeus 14.37-46. Unitas - Revista Eletrônica de Teologia e Ciências das Religiões, Vitória-ES, v. 6, n.1, p. 137-147, jan.-ago., 2018.

SCHUBERT, Kurt. Os partidos religiosos hebraicos da época neotestamentária. São Paulo: Edições Paulinas, 1979.

SIMKOVICH, Malka Zeiger. Greek Influence on the Composition of 2 Maccabees. Journal for the Study of Judaism, Leiden, Vol. 42, p. 293-310, 2011.

SPAER, Arnold; HOUGHTON, Arthur. Sylloge Nummorum Graecorum, Israel. With the assistance of Catherine Lorber. Jerusalem/London: Italo Vecchi Limited, 1998. v. 1: The Arnold Spaer Collection of Seleucid Coins.

ULRICH, Eugene. Daniel, Book of. In: SCHIFFMAN, Lawrence H. Schiffman; VANDERKAM, James C. (Ed.). Encyclopedia of the Dead Sea Scrolls. Oxford: Oxford University Press, 2000. 2 v. p. $170-174$ (I).

VAN DER HORST, Pieter W. Ancient Jewish Bibliomancy. Journal of Greco-Roman Christianity and Judaism, Hamilton, Canada, Vol. 1, p. 9-17, 2000.

VAN DER HORST, Pieter W. Ancient Jewish Epitaphs: An introductory survey of a millennium of Jewish funerary epigraphy (300 BCE - 700 CE). Kampen: Kok Pharos, 1991.

VAN DER HORST, Pieter W. Sortes: Sacred Books as Instant Oracles in Late Antiquity. In: RUTGERS, L. V. et al. (Ed.). The Use of Sacred Books in the Ancient World. Leuven: Peeters, 1998. (Contributions to Biblical Exegesis \& Theology, 22). p. 143-173.

VAN HENTEN, Jan Willelm; AVEMARIE, Friedrich. Martyrdom and Noble Death: Selected Texts from Graeco-Roman, Jewish and Christian antiquity. London/New York: Routledge, 2002. (The context of early Christianity).

VAN HENTEN, Jan Willelm. Jewish Martyrdom and Jesus' Death. In: FREY, Jörg; SCHRÖTER, Jens. (Hg.). Deutungen des Todes Jesu im Neuen Testament. Tübingen: Mohr Siebeck, 2005. (Wissenschaftliche Untersuchungen zum Neuen Testament, 181). p. 139-168.

VAN HENTEN, Jan Willelm. The Maccabean Martyrs as Saviors of the Jewish People: A Study of 2 and 4 Maccabees. Leiden: Brill, 1997. (Supp JSJ, 57).

VERMES, Geza. Ressurreição: história e mito. Rio de Janeiro/São Paulo: Editora Record, 2013.

VERMES, Geza. The Dead Sea Scrolls in English. 2 ed. Harmondsworth: Penguin Books, 1980.

VERSNEL, Henk S. Making Sense of Jesus’ Death: The Pagan Contribution. In: FREY, Jörg; SCHRÖTER, Jens. (Hg.). Deutungen des Todes Jesu im Neuen Testament. Tübingen: Mohr Siebeck, 2005. (Wissenschaftliche Untersuchungen zum Neuen Testament, 181). p. 213-294. 
WEITZMAN, Steven. Josephus on How to Survive Martyrdom. Journal of Jewish Studies, Oxford, Vol. 55, No. 2, p. 230-245, Autumn 2004.

WESTBROOK, Raymond; LEWIS, Theodore J. Who Led the Scapegoat in Leviticus 16:21? Journal of Biblical Literature, Atlanta, GA, Vol. 127, No. 3, p. 417-422, 2008.

WILLIAMS, Jarvis J. Maccabean Martyr Traditions in Paul's Theology of Atonement: Did Martyr Theology Shape Paul's Conception of Jesus' Death? Eugene: Wipf \& Stock, 2010.

WOLFF, Hans Walter. Antropologia do Antigo Testamento. São Paulo: Hagnos, 2008.

WRIGHT, N. T. The Resurrection of the Son of God. Minneapolis: Fortress Press, 2003. (Christian Origins and the Question of God, 3).

Submetido em: 14-2-2019

Aceito em: 19-4-2019 